\title{
Supporting the attentional momentum view of IOR: Is attention biased to go right?
}

\author{
THOMAS M. SPALEK \\ Simon Fraser University, Burnaby, British Columbia, Canada \\ and \\ SHERIEF HAMMAD \\ University of Toronto, Scarborough, Ontario, Canada
}

\begin{abstract}
Inhibition of return (IOR) refers to the finding that individuals are slower to respond to a target presented at a previously attended location than they are to respond to a target presented at a novel location (Posner \& Cohen, 1984). The attentional momentum theory is a recent view of how attention moves around the environment, and it provides an account for the IOR effect that does not rely on an inhibitory mechanism (Pratt, Spalek, \& Bradshaw, 1999). The present paper supports the attentional momentum viewpoint in two ways: first, by replicating the finding that reaction times to targets at the uncued locations are not all the same (Pratt et al., 1999) and second, by showing that responses made to all locations on the cued side of fixation, and not just to the locations that attention had previously traversed, are slower than are responses made to locations on the opposite side of fixation. We also demonstrate that there is a directional bias to the IOR effect that results in the effect's being larger when attention moves in a left-to-right manner.
\end{abstract}

The environment is full of a multitude of stimuli, and at any particular moment in time, our attention can be directed only toward a very small segment of them. Thus, our attentional-orienting system needs to operate in as efficient a manner as possible to ensure our survival. For example, if an animal seeking prey fails to find something at one location, it will be disadvantageous for that animal to keep returning its attention to that location. It will be more efficient to reorient attention to novel locations once searches of previous locations have failed to locate the object of interest. Thus, evolutionarily, a mechanism that favors looking at novel locations would be highly adaptive.

For humans, however, the search for prey and the avoidance of predators are no longer of paramount importance. Nevertheless, humans still actively engage in search behaviors. It is common for a person to be looking for a specific item on a desk or for a particular friend at a party. In these situations, just as it is for animals in the wild, perseverance in looking at one location will result in inefficient search. Thus, it would not be surprising to observe evi-

This research was supported by an NSERC research grant awarded to Steve Joordens, and by an Ontario Graduate Scholarship awarded to the first author. We thank Steve Joordens and Jay Pratt for their assistance with this work, as well as Tram Neill, John McDonald, Brad Gibson, and an anonymous reviewer for helpful comments on earlier versions of this article. Correspondence concerning this article should be addressed to T. M. Spalek, Department of Psychology, Simon Fraser University, Burnaby, BC, V5A 1S6, Canada (e-mail: tspalek@sfu.ca).

Note-This article was accepted by the previous editorial team, headed by Neil Macmillan. dence for a mechanism that favors orienting to novel locations in the human attentional system.

The focus of the present paper is on the mechanism that underlies this bias for orienting toward novel locations in humans. The examination will be restricted to the adult population and, specifically, to a phenomenon termed inhibition of return (IOR). To this end, the phenomenon will first be described, and a brief overview of some of the evidence supporting the existence of inhibitory processes underlying attentional orienting will be provided. Following the description of the inhibitory account, an alternative account based on attentional momentum will be described. According to the attentional momentum account of IOR, once attention is set in motion, it tends to continue moving along that vector. Past evidence in favor of the attentional momentum notion will be briefly provided, and then several experiments, the motive of which was to further test the attentional momentum account, will be presented.

\section{Is There Evidence for a Novelty-Biased Search Mechanism?}

Posner and Cohen (1984) conducted an experiment that had three possible target locations, one centrally located on the screen and the other two on either side of the first. Individuals were instructed to keep their eyes at the center location and to respond when they saw a target. During a trial, one of the peripheral locations would be cued by briefly flickering the outline of the box (this box will subsequently be referred to as the cued location), followed after some variable time interval by the target, which could appear in any of the three boxes. The participants were in- 
structed to press a response button as quickly as possible when they detected the appearance of the target.

The results of this experiment revealed an interesting dissociation. If the target was presented less than $200 \mathrm{msec}$ after the cue, the participants were quicker to respond if the target appeared in the cued location than if it appeared in the other peripheral location on the opposite side of fixation (referred to as the uncued location). In contrast, if more than $300 \mathrm{msec}$ had elapsed between the cue and the target, the opposite pattern emerged. That is, the participants were now slower to respond to a target at the cued location. The latter finding Posner, Rafal, Choate, and Vaughan (1985) have termed the IOR effect.

Since its initial discovery by Posner and Cohen (1984), IOR has been found in a host of different empirical contexts. For example, it has been found when a central fixation cue is used, rather than letting attention naturally return to fixation between the initial cue and the target (e.g., Posner \& Cohen, 1984). The type of response does not seem to be critical, because IOR has been observed when a simple manual keypress (e.g., Reuter-Lorenz, Jha, \& Rosenquist, 1996), a choice manual keypress (e.g., Maylor, 1985), or an overt eye movement (e.g., Abrams \& Dobkin, 1994; Vaughan, 1984) has been required. The IOR effect has also been observed when identification of the target is required, rather than just a simple detection response (Chasteen \& Pratt, 1999; Lupiáñez, Milán, Tornay, Madrid, \& Tudela, 1997; Pratt, 1995; Pratt, Kingstone, \& Khoe, 1997; but see Tanaka \& Shimojo, 1996, and Terry, Valdes, \& Neill, 1994, for contrary findings). IOR has been founded with psychophysical measures (e.g., Handy, Jha, \& Mangun, 1999), as well as with electrophysiological measures (e.g., McDonald, Ward, \& Kiehl, 1999). IOR has been found in various modalities other than the visual domain and even cross-modally (auditory, MacDonald \& Ward, 1999, Mondor, 1999, and Schmidt, 1996; tactile, Röder, Spence, \& Rösler, 2000; cross-modal, Spence \& Driver, 1998, and Spence, Lloyd, McGlone, Nicholls, \& Driver, 2000). Thus, the IOR effect has proven to be quite a robust phenomenon.

\section{Inhibition Account}

One popular explanation of Posner and Cohen's (1984) data is that the presentation of the cue automatically pulls the individual's attention to the cued location (cf. Yantis \& Jonides, 1990). If the target is presented shortly afterward, attention is still at that cued location, and as a result, a response can be made quickly, relative to when the target is at the uncued location and a reallocation of attention would be required. However, it is assumed that after approximately $200 \mathrm{msec}$, attention naturally returns to the central location, because that is the location that minimizes the distance to all possible target locations, as well as being the place where the participant's eyes are fixating. According to this account, once attention is moved away from the cued location, inhibition is directed at the cued location (Posner \& Cohen, 1984). If attention was required to return to the cued location, that inhibition would have to be overcome, and this would result in longer reac- tion times (RTs) to a target presented at the cued location, relative to a target presented at the uncued location. Thus, inhibition is one possible mechanism by which attention might be biased toward moving to novel locations, because, at these locations, no inhibition would have to be overcome.

The previous discussion has focused on inhibition at the attentional level. However, many researchers have argued instead for a different locus for the inhibition. One alternative that has been proposed is that once attention moves away from the cued location, sensory processing at that location is inhibited (Berlucchi, Chelazzi, \& Tassinari, 2000). Thus, it is not that it takes longer to move attention to the cued location and engage it there but, instead, that the uptake of information from the cued location will be slower. Another alternative is that the inhibition occurs at the (motor) level of eye movements (Rafal, Calabresi, Brennan, \& Sciolto, 1989; Taylor \& Klein, 1998), which are usually preceded by movements of attention. According to this view, if an eye movement has been planned to a location (whether it is executed or not), a future eye movement to that location is inhibited. Thus, if the target appeared at the cued location, resulting in the programming of another eye movement to that location, the inhibition would have to be overcome and would again result in slower responses. Evidence exists in favor of and against all of these different viewpoints, but which specific inhibitory view is correct is not important for the present article. All of these views would make the same prediction, which is that inhibition (be it at a sensory, attentional, or motor level) would be directed at the cued location and responses to that location would be slower. Thus, for purposes of future discussion, the level at which inhibition occurs will be ignored, and these views will be referred to collectively as the inhibitory view.

\section{Alternative to Inhibition}

The finding that individuals are slower to respond to a target at a previously attended location supports the notion that we have a mechanism in place that favors novelty. However, inhibition is not the only mechanism by which these results could be obtained. Prior to accepting the notion that an inhibitory mechanism underlies the bias toward novel locations, it is important that other views be considered.

One such alternative, termed attentional momentum, was forwarded by Pratt, Spalek, and Bradshaw (1999). According to the attentional momentum theory, attention has associated with it a characteristic closely akin to the physical property of momentum. Thus, once attention starts moving in a direction, it tends to continue moving in that direction until some force (effort) is directed against it.

Thus, an attentional momentum account of the findings by Posner and Cohen (1984) would go as follows. When the target appears within $200 \mathrm{msec}$ of the cue, the explanation is identical to the inhibition account. That is, attention is drawn to, and is still at, the cued location when the target appears, allowing a detection response to be made relatively quickly. However, the explanations differ in 
terms of what happens after the $200 \mathrm{msec}$ have elapsed and attention then disengages from the cued location and moves back to the central location. According to the attentional momentum theory, no inhibition is directed at the cued location. Instead, attention is moving in the direction from the cued location to the central location, and it will continue moving in that direction unless some effort is applied to change that direction. The uncued location is simply further along the path that attention was already moving in, and so no effort is required to change the path of attention. The greater the change in direction, the greater the effort required. The cued location, being in a direction completely opposite to the path that attention is moving along, thus, requires a considerable effort for attention to be reoriented back to the cued location. The amount of effort required to alter the path of attention results in a proportional slowing in responding, and so slower responses will be expected to a target presented at the cued, as compared with the opposite, location. An analogy would be coming to an intersection while driving a car. It is trivial for you to continue moving forward along some road. However, if you had missed your destination and were required to make a U-turn, that would require considerable effort and would be much slower to accomplish.

\section{Inhibition Versus Attentional Momentum}

Given that there are at least two possible explanations for the IOR phenomenon, the next task is to attempt to rule out one of those explanations. In Posner and Cohen's (1984) original work, there was another experiment reported in which they had four peripheral target locations in addition to the central location. The peripheral locations were equidistant from the central location, one to the left, one to the right, one above, and one below (i.e., a "+" pattern). According to Posner and Cohen, at an SOA of $500 \mathrm{msec}$, "the opposite position is no faster than the two orthogonal positions, while all three positions are faster than the cued one" (p. 538). This finding is not what would be predicted on the basis of the attentional momentum account. According to the attentional momentum account, response to the opposite location should be the fastest, since attention does not have to change direction at all; next fastest should be the response to the two adjacent locations, because there is a $90^{\circ}$ change in direction; and the response to the cued location should be the slowest, because that requires a $180^{\circ}$ change in direction. Therefore, on the basis of Posner and Cohen's results, one might conclude that the attentional momentum view is incorrect.

However, Posner and Cohen (1984) did not report the actual values associated with the various locations or the number of participants that were tested. Thus, it is unclear whether the lack of a difference between the opposite and the adjacent locations was merely due to a lack of power. Pratt et al. (1999) conducted several experiments pitting the attentional momentum theory against three different instantiations of the inhibition view (inhibited location, spreading inhibition, and inhibited hemifield) that have been put forth over the last 2 decades. One of these experiments was very similar to that in Posner and Cohen's study, with four possible target locations again arranged equidistantly one above, one below, one to the left, and one to the right of a fixation point. Unlike Posner and Cohen, Pratt et al. (1999) found that the RTs to targets differed between the uncued locations. In fact, the pattern of RTs was exactly as would be predicted on the basis of attentional momentum. That is, responses to the opposite location were the fastest, and those to the two adjacent locations were significantly slower than those to the opposite location, yet still significantly faster than those to the cued location (see also Pratt, Adam, \& McAuliffe, 1998, for similar results). In fact, in all of the experiments conducted by Pratt et al., the results came out in favor of the attentional momentum view and contrary to the inhibition views.

Another study whose results appear to raise some problems for the attentional momentum view is the one by O'Donnell and Pratt (1996, Experiment 1). In this study, O'Donnell and Pratt had four possible target locations arranged horizontally, with two locations on either side of fixation (one termed the near location, and one termed the far location, depending on their distance from fixation). A cue could appear at any of the four possible locations, followed by a fixation cue and then a target at any of the four possible locations. According to the attentional momentum account, it is the direction of attention that is critical, and it should not matter if that direction is induced by a near or a far cue. Thus, responses made to targets presented at either of the locations on the cued side of fixation should always be slower than responses made to targets presented at locations on the opposite side of fixation.

Generally, O'Donnell and Pratt (1996) found that responses to targets presented on the cued side were made more slowly than responses to equally eccentric targets presented on the opposite side. However, a result that appears to raise problems for the attentional momentum view occurred when a near location was cued and responses to targets at the far locations were examined. According to O'Donnell and Pratt, there were no differences in RTs between the two far locations. However, close examination reveals that the RTs in this condition were in the direction that would be predicted by the attentional momentum account. Specifically, the far location on the cued side was responded to $4 \mathrm{msec}$ more slowly than the far location on the opposite side. Given that the IOR effect at the near locations was only $13 \mathrm{msec}$ and that only 12 participants completed the experiment, the possibility exists that the lack of significance in the far condition was simply due to a statistical power issue. Thus, replicating the effect with more participants and, if possible, a larger IOR effect would be prudent before discounting the attentional momentum view on the basis of this one problematic finding.

Overall then, it is unclear whether the attentional momentum account should be considered a viable alternative to the traditional inhibitory accounts of IOR. Although Posner and Cohen (1984) found no evidence for differential responding to the uncued locations, Pratt et al. (1998; Pratt et al., 1999) did find such evidence. As well, al- 
though O'Donnell and Pratt's (1996) results for the condition when a near location was cued seem to go against the predictions of the attentional momentum theory, those results may simply have been the result of insufficient statistical power. Therefore, a further examination of these issues needs to be carried out in order to assess the legitimacy of attentional momentum as an explanatory view of IOR.

\section{The Present Study}

In the present paper, we examined whether the attentional momentum notion should be considered a reasonable alternative to the inhibitory explanations for the IOR effect. This was accomplished in two ways. First, given the theoretical importance of determining whether RTs are different at the uncued locations and the fact that there are conflicting reports from Pratt et al. (1999) and Posner and Cohen (1984), using nearly identical procedures, it was prudent to reexamine this issue to see which set of results would be replicated. Second, the findings of O'Donnell and Pratt (1996) may have suffered from statistical power issues that resulted in the failure to observe IOR in the far locations following a near cue. Given the importance of these results from the standpoint of theory discrimination, a replication of this work within a more powerful design is critical.

Another issue that is addressed in this article is the extent to which contextual factors influence the IOR effect. Some work in this domain has already been done. For example, Reuter-Lorenz et al. (1996) observed that changing the target intensity relative to the cues influenced the size of the IOR effect. That is, if the target was presented with a lower intensity than were the cues, the IOR effect was larger in magnitude than if the target was presented at a higher intensity than the cues. In the present article, we examine whether the direction of implied motion based on the cues also influences the size of the IOR effect. In the memory domain, a phenomenon known as representational momentum (Freyd \& Finke, 1984) has been shown to be influenced by the direction of implied motion. That is, participants' memory for the final position of an object was biased toward being further along the path of motion when the implied motion was from left to right (Halpern \& Kelly, 1993) or from top to bottom (Hubbard, 1990). However, in IOR, this bias has not been examined, because there was no reason to suspect that it had any influence, and collapsing over that variable increased the power of the study.

To foreshadow the results of the present study, Experiments 1, 2, and 3 all replicated Pratt et al.'s (1999) findings that RTs to targets presented at the uncued locations differ depending on their position relative to the attentional path. The results of Experiment 1 also indicated that the problematic findings of O'Donnell and Pratt (1996) were indeed the result of statistical power issues, because IOR was observed at the far locations following a near cue when a larger sample size was used. Thus, both of these results support the attentional momentum viewpoint. Experiment 1 also provided initial evidence for a directional bias to the IOR effect. In Experiment 2, the directional bias effect was investigated in more detail and the independent contributions of a top-to-bottom bias and a leftto-right bias to the IOR effect were separated out. Finally, Experiment 3 replicated the findings of Experiment 2, but without a cue back to fixation to make sure that the directional bias observed was not due to apparent motion.

\section{EXPERIMENT 1}

The present experiment was designed to investigate three issues. This was accomplished by setting up a situation in which there were eight possible target locations arranged in an "X" pattern (see Figure 1). The first issue was to examine whether participants' RTs to targets at various uncued positions would be equal or not. If all of the uncued positions were to be responded to equally quickly, this would support Posner and Cohen's (1984) view that only the cued location was inhibited. If the opposite locations were to be responded to more quickly than the adjacent locations and all of these locations were to be responded to more quickly than the cued location, this would support the attentional momentum view. The second issue investigated in the present experiment was whether all of the locations on the cued side of fixation would be responded to more slowly than the locations on the opposite side of fixation. This should occur regardless of which location is initially cued, according to the attentional momentum account, but would be contrary to some of the findings of O'Donnell and Pratt (1996). Finally, the issue of whether a bias would be present in the IOR effect was also investigated. If the IOR effect were to be systematically larger in one direction than in the others, this would suggest that attention might be predisposed to move in that direction.

\section{Method}

Participants. Forty-one 1st-year psychology students attending the University of Toronto at Scarborough participated in this study. They received course credit for their participation. All had normal or corrected-to-normal vision.

Procedure. The participants were asked to sit in front of a monitor and keyboard so that their eyes were at a distance of $30 \mathrm{~cm}$ from the screen. Instructions were presented to the participants in written form and then were repeated verbally to ensure that they had been fully understood. Before proceeding with the trials, the participants were reminded to remain at a distance of $30 \mathrm{~cm}$ from the monitor and to keep their eyes on the fixation point for the course of the experiment. A typical trial sequence would be as follows. Upon commencement of the trials, eight placeholder boxes (each having a length and width of $1.53^{\circ}$ of visual angle) arranged in an " $X$ " pattern were presented on the screen. At the center of the " $X$ " was the fixation point that the participants were instructed to keep their eyes on. Four placeholders were positioned $6.47^{\circ}$ of visual angle away from the fixation point along each diagonal (near locations), and four were positioned at $12.77^{\circ}$ of visual angle away from the fixation point along each diagonal (far locations). The placeholders served as potential locations for cue and target stimuli.

For $1,500 \mathrm{msec}$, the placeholders were the only stimuli visible on the screen; then an initial cue (a filled-in circle with a diameter of $1.15^{\circ}$ of visual angle) was presented inside one of placeholders. The cue had an equal probability of occurring inside any one of the eight 


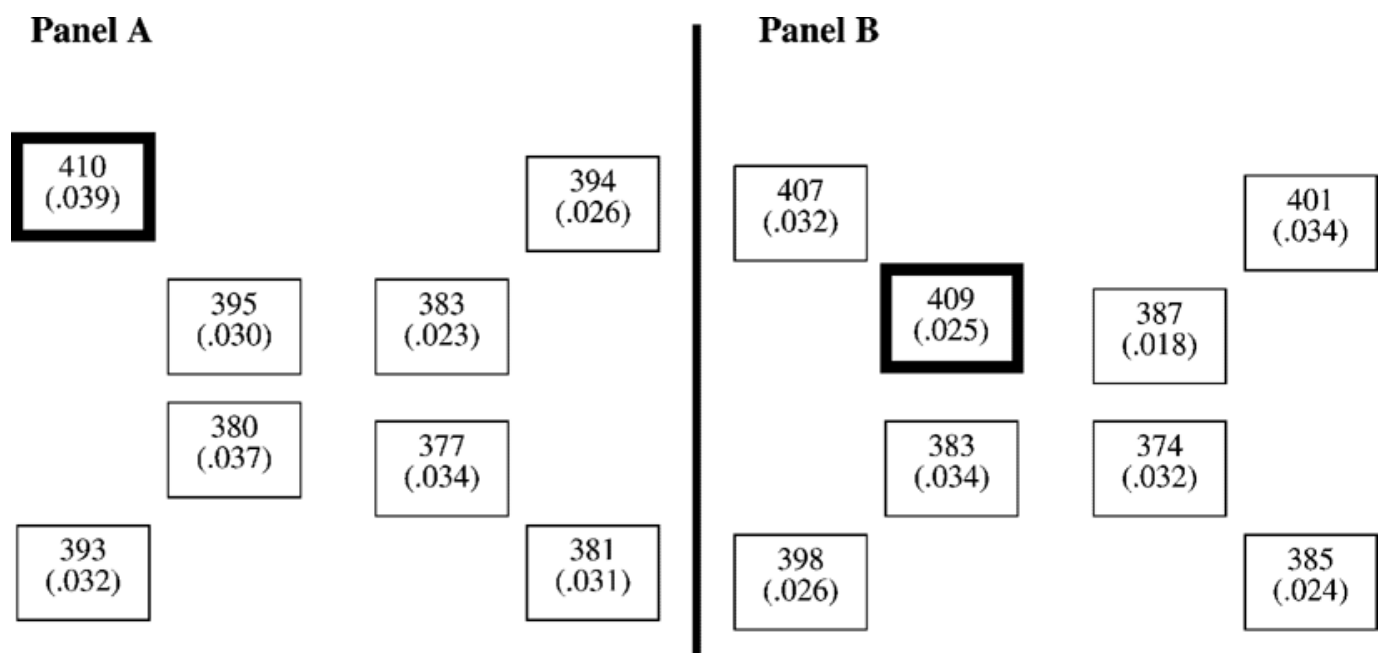

Figure 1. Experiment 1, " $X$ " condition. Mean reaction times (in milliseconds) to target locations (mean response errors shown in parentheses) in the (A) far-cue and (B) near-cue conditions (cue locations highlighted).

placeholders and were presented for $300 \mathrm{msec}$. After the initial cue was removed, there was a delay of $200 \mathrm{msec}$, with only the placeholders on the screen. After this delay, a second cue (again a filledin circle with a diameter of $1.15^{\circ}$ of visual angle) was presented at the fixation point for $300 \mathrm{msec}$. This was followed by another delay of $150 \mathrm{msec}$, again with only the placeholders present. After this second delay, the target stimulus (a filled-in square with a length and width of $1.15^{\circ}$ of visual angle) was presented in one of the placeholders. As with the initial cue, the target had an equal probability of occurring in any of the eight placeholders. The participants were required to respond as soon as they saw the target by pressing the space bar on the keyboard with their right hands. The target remained on the screen for $1,000 \mathrm{msec}$. The RT was recorded as the interval between the onset of the target and the time at which the participant pressed the space bar. The removal of the target indicated the conclusion of the trial.

To discourage the participants from simply getting into a rhythm of pressing the space bar at certain times, catch trials were randomly interspersed among the test trials. A catch trial was identical to a test trial, with the exception that no target was presented after the central fixation cue. If the participant pressed the space bar during a catch trial, responded at any point in time before the presentation of the target, or failed to respond within $1,000 \mathrm{msec}$ of the presentation of the target on a test trial, the trial was coded as an error, and an error tone was presented.

Design. Experiment 1 consisted of two blocks of trials. Each block began with 15 practice trials, followed by 384 experimental trials, 64 of which were randomly assigned as catch trials. Importantly, the presentation of the initial cue was in no way informative of the location of the target, since both the cue and the target had an equal probability of occurring in any of the eight placeholder locations. At the end of the first block of trials, a self-paced break was given to the participant. The participants could continue on to the second block at their leisure by depressing any key. On average the participants took a break approximately $2 \mathrm{~min}$ in length.

Materials and Apparatus. An IBM-compatible microcomputer was used to present all visual information, which was displayed on a 14-in. color monitor. The fixation diamond was centered on the screen both horizontally and vertically. All the stimuli were presented in white on a black background. The participants made their responses with a standard keyboard. The program was written in Quick Basic 4.5, with millisecond timing routines provided by
Graves and Bradley $(1987,1988)$. Copies of the code are available upon request.

\section{Results and Discussion}

General. The RTs for correct trials were analyzed with a three-way repeated measures analysis of variance (ANOVA), with the side of the target relative to the side of the cue (same, opposite, left, or right), cue eccentricity (far vs. near), and target eccentricity (far vs. near) as withinsubjects variables. All the participants were at least $80 \%$ accurate on the catch trials. The mean RTs for each condition are illustrated in Figure 1 (mean errors for these conditions are indicated in parentheses). To compensate for the possible increase in family-wise error rate, all planned comparisons were evaluated using an alpha of .005.

Analyses revealed a significant main effect of side $\left[F(3,120)=53.68, M S_{\mathrm{e}}=352.38, p<.0001\right]$. As was predicted, the responses to the same (cued) side $(M=$ $405 \mathrm{msec}$ ) were slower than responses to the opposite side $(M=379 \mathrm{msec})$, whereas responses to the left $(M=$ $391 \mathrm{msec})$ and right $(M=388 \mathrm{msec})$ adjacent sides were in between the two. This pattern of RTs is consistent with the pattern that would be predicted by attentional momentum.

There was a significant main effect for cue eccentricity $\left[F(1,40)=7.14, M S_{\mathrm{e}}=311.17, p=.011\right]$, with responses to targets following a far cue $(M=389 \mathrm{msec})$ being faster than those to targets following a near cue $(M=393 \mathrm{msec})$. The main effect of target eccentricity was also significant but was opposite in direction $\left[F(1,40)=54.85, M S_{\mathrm{e}}=\right.$ $285.47, p<.0001$ ], with responses to targets at far locations $(M=396 \mathrm{msec})$ being slower than responses to targets at near locations $(M=386 \mathrm{msec})$.

A trend for the interaction between side and target eccentricity $\left[F(3,120)=2.47, M S_{\mathrm{e}}=236.66, p=.065\right]$ was also observed. This interaction was the result of the target eccentricity effect's being greater in the left $\left(M_{\text {far }}=\right.$ 
$\left.397 \mathrm{msec}, M_{\text {near }}=385 \mathrm{msec}\right)$ and $\operatorname{right}\left(M_{\mathrm{far}}=395 \mathrm{msec}\right.$, $\left.M_{\text {near }}=381 \mathrm{msec}\right)$ adjacent conditions than in either the same ( $\left.M_{\text {far }}=408 \mathrm{msec}, M_{\text {near }}=402 \mathrm{msec}\right)$ or the opposite $\left(M_{\text {far }}=382 \mathrm{msec}, M_{\text {near }}=375 \mathrm{msec}\right)$ side conditions. There was also a three-way interaction of side, cue eccentricity, and target eccentricity $\left[F(3,120)=3.67, M S_{\mathrm{e}}=\right.$ $292.38, p=.014]$. When a far cue preceded the target, a significant difference in RTs was observed between far and near targets at all locations, except on the opposite side of the cue (same, $M_{\text {far }}=409 \mathrm{msec}, M_{\text {near }}=395 \mathrm{msec}$; left, $M_{\mathrm{far}}=393 \mathrm{msec}, M_{\text {near }}=383 \mathrm{msec}$; right, $M_{\mathrm{far}}=$ $392 \mathrm{msec}, M_{\text {near }}=379 \mathrm{msec}$; opposite, $M_{\text {far }}=380 \mathrm{msec}$, $M_{\text {near }}=377 \mathrm{msec}$ ). When a near cue was presented, a significant difference was observed in RTs between far and near targets at all locations, except when targets were presented on the same side as that on which the cue was presented (same, $M_{\mathrm{far}}=406 \mathrm{msec}, M_{\text {near }}=406 \mathrm{msec}$; left, $M_{\text {far }}=400 \mathrm{msec}, M_{\text {near }}=386 \mathrm{msec}$; right, $M_{\text {far }}=$ $397 \mathrm{msec}, M_{\text {near }}=382 \mathrm{msec}$; opposite, $M_{\mathrm{far}}=384 \mathrm{msec}$, $M_{\text {near }}=374 \mathrm{msec}$ ).

The longer RTs to targets presented at the cued location, than to targets presented at any of the uncued locations demonstrates the basic IOR effect. This on its own does nothing to distinguish between the inhibited location theory of Posner and Cohen (1984) and the theory of attentional momentum suggested by Pratt et al. (1999). On the other hand, the fact that the responses to targets at the adjacent uncued locations were made more slowly than responses to targets at locations on the opposite side, which was also an uncued location, does distinguish between the two theories. An inhibited location hypothesis would have predicted equal RTs to all uncued locations and so fails to explain this finding. However, these findings are completely consistent with the findings of Pratt et al. (1999), and in keeping with the tenets of attentional momentum.

Testing O'Donnell and Pratt (1996). In order to analyze the data in the same way as O'Donnell and Pratt, four planned comparison $t$ tests were conducted on the RTs to targets at equally eccentric locations that were on the same and opposite sides of fixation from the initial cue. Thus, the RTs to targets presented at the near locations were compared with one another, and the RTs to targets presented at the far locations were compared with one another. These comparisons were further broken down by whether the initial cue was at a near or a far location. When the initial cue was presented at one of the far locations and the target also appeared at one of the far locations, a significant difference in RTs was observed between targets presented on the same side of fixation as that on which the cue was presented $(M=410 \mathrm{msec})$ and targets presented on the opposite side of fixation from that on which the cue was presented $[M=381 \mathrm{msec} ; t(40)=$ $6.03, p<.0001]$. When the initial cue was at one of the far locations and the target was presented at one of the near locations, the same pattern of results occurred $[M=395$ and $377 \mathrm{msec}$ for the same and the opposite target locations, respectively; $t(40)=4.38, p<.0001$ ].

When the initial cue was instead presented at one of the near locations and the target also appeared at one of the near locations, a significant difference in RTs was observed between targets presented on the same side of fixation as that for the cue $(M=409 \mathrm{msec})$ and targets presented on the opposite side of fixation from that for the cue $[M=374$ msec; $t(40)=8.25, p<.0001]$. Finally, when the initial cue was presented at one of the near locations and the target was presented at one of the far locations, again the same pattern of results was observed [ $M=407$ and $385 \mathrm{msec}$ for the same and the opposite target locations, respectively; $t=5.80, p<.0001]$.

Recall that O'Donnell and Pratt (1996) claimed that inhibition was directed at all locations over which attention had previously passed. According to their view, IOR should have been found in all conditions except when the initial cue was at one of the near locations and the target was at one of the far locations. Whereas in their study they failed to find a significant difference in RTs to targets at the far locations when a near location was cued, the present study did find a significant difference. All of the other results of O'Donnell and Pratt were replicated. As has been pointed out previously, the results of O'Donnell and Pratt that failed to be replicated in the present study may have simply suffered from a lack of power due to the relatively small number of participants tested and the fact that their effects were smaller than those in the present study. The finding of IOR in all the conditions is completely consistent with what would be predicted on the basis of the attentional momentum account.

Directional bias. Evidence from the memory literature has suggested that if an object is implied to be moving, a participant's memory for the final location of that object will be slightly further along the implied path of motion than was actually the case. This effect is even greater if the object is being displaced in a left-to-right direction (Halpern \& Kelly, 1993) or a top-to-bottom direction (Hubbard, 1990). The present study allows the investigation of whether similar directional biases are present in the attentionaldomain (specifically, within the IOR phenomenon).

The investigation of whether directional biases are present in IOR was accomplished by separating out the participants' performance according to the location of the initial cue. For example, if the directional bias in IOR was the same as it is in the representational momentum phenomenon, one would expect there to be a large difference between the IOR effect observed in locations along the "I" arm of the " $X$ " display and not much difference between the IOR effects along the "/" arm of the "X" display, due to the fact that if one cued the top most position of the "l" arm and then cued fixation, attention would be moving from left to right and from top to bottom. Thus, if attention was biased to move in this direction, continuing the attentional movement to the opposite location would be consistent with the biases and so should be accomplished quickly. On the other hand, returning attention to the cued location would require going completely against both biases and thus should be accomplished slowly. Therefore, any IOR effect that is normally present should be enhanced in this situation. However, if one cued the bottommost position of the "I" arm and then cued fixation, at- 


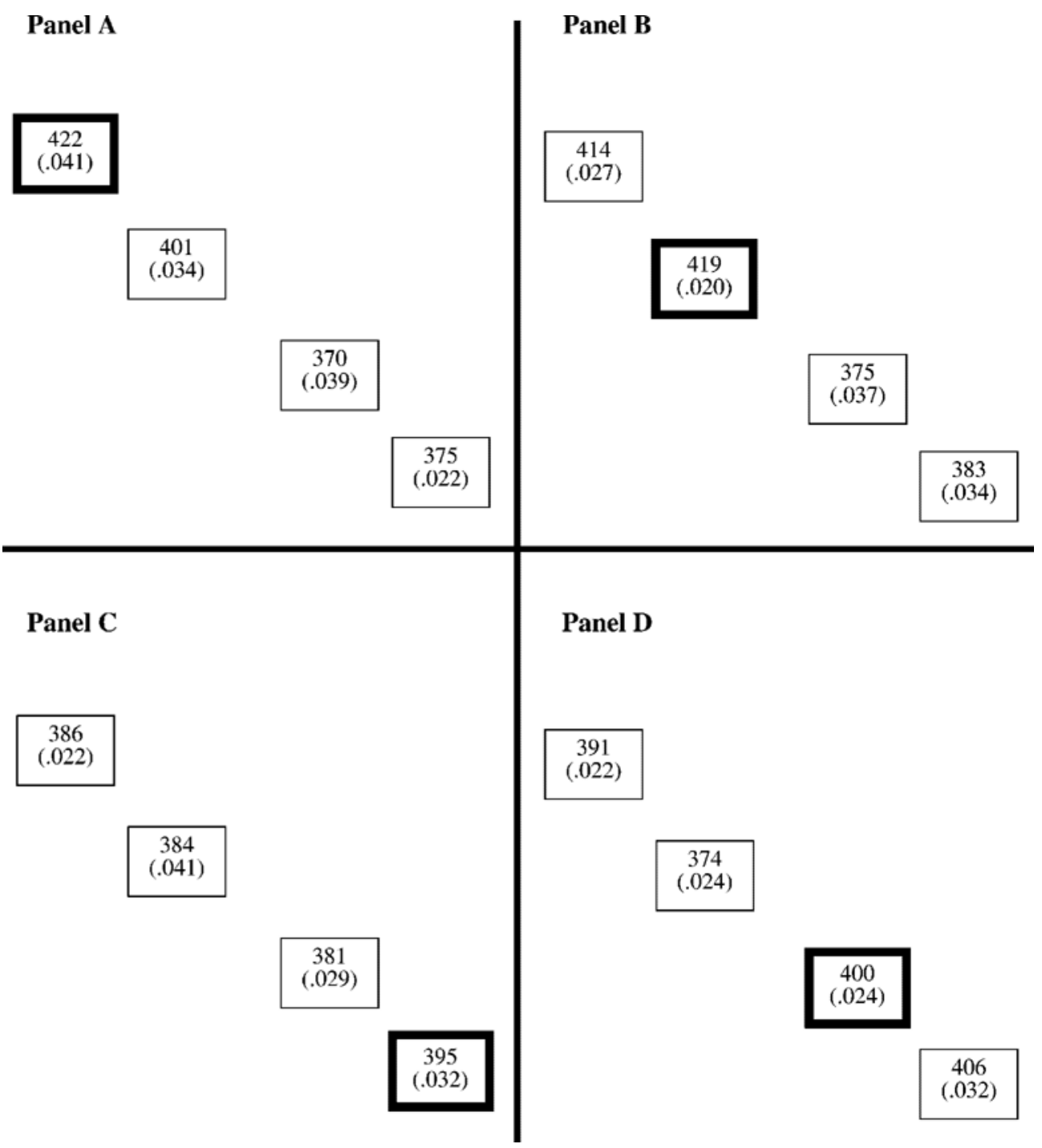

Figure 2. Experiment 1, " " condition. Mean reaction times (in milliseconds) to target locations (mean response errors shown in parentheses) in the (A) far-cue/left-right, (B) near-cue/left-right, (C) farcue/right-left, and (D) near-cue/right-left conditions (cue locations highlighted).

tention would be moving from right to left and from bottom to top. Now continuing along the attentional path would go against both of the biases, whereas returning back to the cued location would be consistent with the biases. Therefore, in this condition, the IOR effect would be expected to be attenuated. Performance along the "/" arm would be expected to yield IOR effects that are intermediate to those in the conditions above, because in those situations moving attention to the opposite location or returning to the cued location would agree with one of the biases but would conflict with the other and, thus, the biases should cancel one another out to some extent. Thus, by looking at the performance along the "/" arm, it can be determined whether either bias is stronger than the other.

The uncollapsed means are presented in Figures 2 and 3 , with the full set of analyses presented in the Appendix.
For the sake of brevity and given that the results are fairly consistent across the conditions, only the collapsed results will be discussed. The RTs were collapsed across near and far cues and near and far target locations, leaving us with RTs to targets on the same and the opposite sides of fixation for each of the four possible implied directions of motion. Thus, the RTs for correct trials were analyzed with a 2 (side: same or opposite) $\times 4$ (direction: left to right and top to bottom, left to right and bottom to top, right to left and bottom to top, and right to left and top to bottom) repeated measures ANOVA. ${ }^{1}$ Mean RTs for each of the collapsed conditions are presented in Table 1 .

The analysis revealed a main effect of side $[F(1,40)=$ $\left.87.34, M S_{\mathrm{e}}=621.72, p<0001\right]$, with RTs to targets on the same side as that for the cue $(M=405 \mathrm{msec})$ being longer than those to targets on the opposite side from that 
Panel A

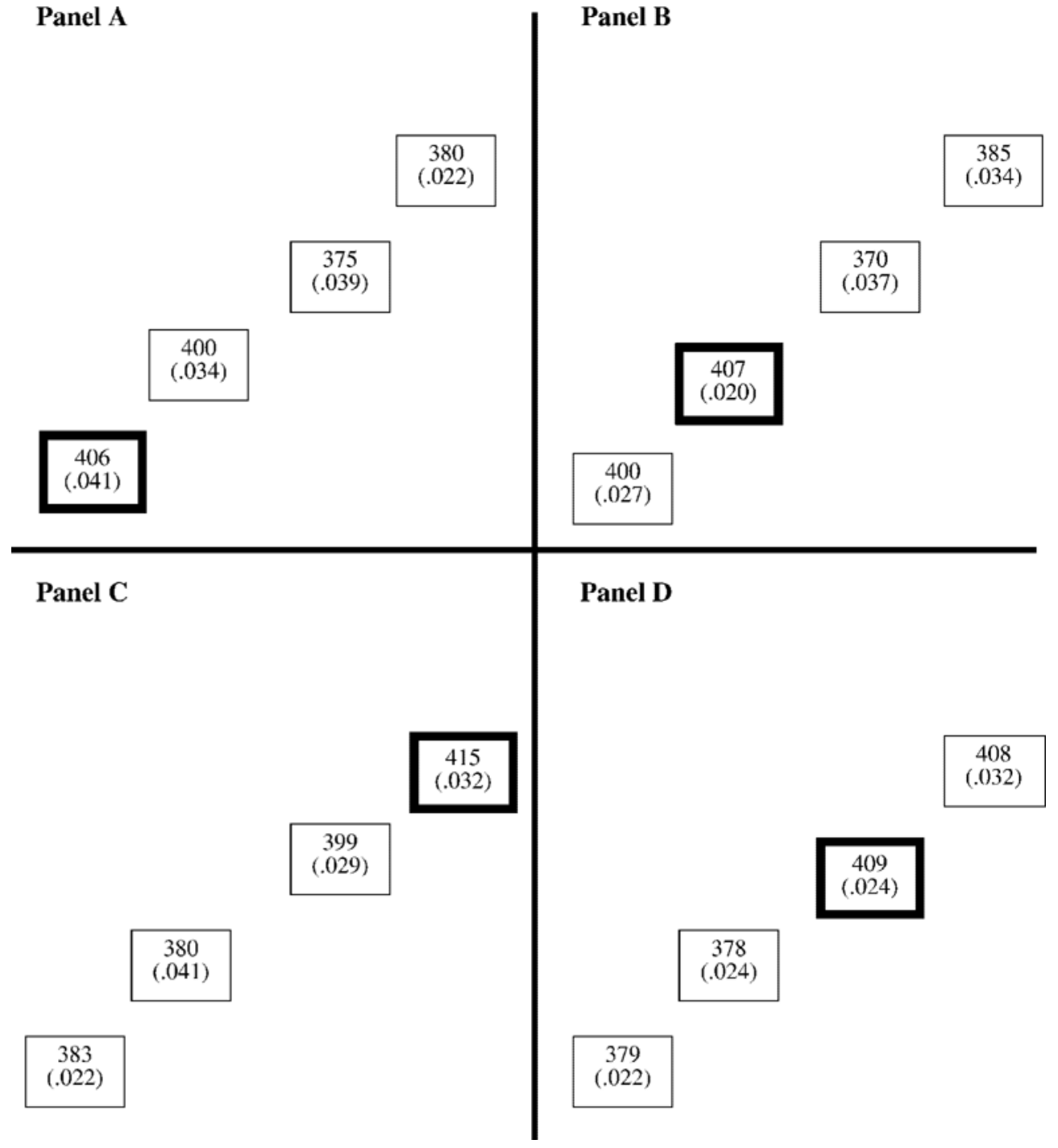

Figure 3. Experiment 1, “”” condition. Mean reaction times (in milliseconds) to target locations (mean response errors shown in parentheses) in the (A) far-cue/left-right, (B) near-cue/left-right, (C) farcue/right-left, and (D) near-cue/right-left conditions (cue locations highlighted).

for the cue $(M=379 \mathrm{msec})$. This was indicative of the basic IOR effect. There was a significant interaction between side and direction $\left[F(3,120)=10.00, M S_{\mathrm{e}}=\right.$ $232.60, p<.0001]$. Planned comparisons revealed that the difference in RTs between same and opposite sides (IOR) was greatest when attention moved from left to right and from top to bottom $\left(M_{\text {same }}=414 \mathrm{msec}, M_{\text {opposite }}=\right.$ $376 \mathrm{msec}$, IOR $=38 \mathrm{msec})$, next most when attention moved from left to right and from bottom to top $\left(M_{\text {same }}=\right.$ $403 \mathrm{msec}, M_{\text {opposite }}=378 \mathrm{msec}$, IOR $=25 \mathrm{msec}$ ) or from

Table 1

Mean Reaction Times for Same and Opposite Conditions Across the Four Directions of Implied Motion in Experiment 1

\begin{tabular}{lccccc}
\hline & \multicolumn{4}{c}{ Direction of Implied Motion } \\
\cline { 2 - 3 } \cline { 5 - 6 } Condition & \multicolumn{2}{c}{ Left to Right } & & \multicolumn{2}{c}{ Right to Left } \\
\cline { 2 - 3 } \cline { 5 - 6 } & Top to Bottom & Bottom to Top & & Top to Bottom & Bottom to Top \\
\hline Same & 414 & 403 & & 407 & 396 \\
Opposite & 376 & 378 & & 380 & 384 \\
IOR effect & $38^{*}$ & $25^{*}$ & & $27^{*}$ & $12^{*}$ \\
\hline
\end{tabular}

$* p<.05$, two-tailed. 
right to left and from top to bottom $\left(M_{\text {same }}=408 \mathrm{msec}\right.$, $M_{\text {opposite }}=380 \mathrm{msec}$, IOR $=28 \mathrm{msec}$ ), where these two differences were equal to one another, and least when attention moved from right to left and from bottom to top $\left(M_{\text {same }}=396 \mathrm{msec}, M_{\text {opposite }}=384 \mathrm{msec}\right.$, IOR $=12$ msec). The fact that there was a difference between the IOR effects in the "I" arm suggests that attention is indeed biased toward left-to-right or top-to-bottom movement or both. The fact that there was no difference between the IOR effects in the "/" arm suggests that the left-to-right bias is of the same strength as the top-to-bottom bias. Thus, both biases seem to be present in the IOR effect.

\section{EXPERIMENT 2}

Experiment 1 provided evidence that both the left-toright and the top-to-bottom biases are present in the IOR effect. However, to this point, these two biases have not been examined independently of one another. Given that both biases have been documented in the representational momentum literature, it is important to look at the contributions from each of these biases separately. Thus, in the present experiment, the four locations were arranged in a "+" pattern, so that any left-to-right bias could be examined independently from any top-to-bottom bias.

\section{Method}

Participants. The participants were 28 1st-year psychology students from the University of Toronto at Scarborough, who had not taken part in Experiment 1. They received course credit for their participation. All had normal or corrected-to-normal vision.

Procedure. As in Experiment 1, the participants were asked to sit in front of a monitor and keyboard so that their eyes were at a distance of approximately $30 \mathrm{~cm}$ from the screen. Instructions were presented to the participants in written form and then were repeated verbally to ensure that they had been fully understood. The trial sequence was identical to that in Experiment 1.

The only difference between Experiments 1 and 2 was that only four placeholders were used in Experiment 2 and they were oriented in a "+" pattern centered on the fixation diamond (see Figure 4). Each of the four locations was $12.77^{\circ}$ of visual angle away from fixation.

Design. Experiment 2 was made up of two blocks of trials. Each block began with 15 practice trials, followed by 384 test trials, 64 of which were randomly assigned as catch trials. Both the cue and the target had an equal probability of occurring in any of the four placeholders. Prior to each block of trials, a set of instructions was presented in written form. At the end of the first block of trials, a selfpaced break was given to the participant. The participants could continue on to the second block at their leisure by depressing the "g" key. On average, the participants took a break approximately 2 min in length.

Apparatus and Materials. The apparatus and materials for the present experiment were identical to those in Experiment 1.

\section{Results and Discussion}

The RTs for 4 of the participants were excluded, due to the fact that in one of the conditions their mean differed by more than two standard deviations from the mean for the rest of the participants. The RTs for the correct trials from the remaining 24 participants were analyzed with a twoway repeated measures ANOVA, with direction (left to right, right to left, top to bottom, and bottom to top) and side (same, opposite, adjacent left, and adjacent right) as within-subjects variables. All the participants were at least $80 \%$ accurate on the catch trials. The mean RTs for each condition are illustrated in Figure 4 (mean errors for these conditions are indicated in parentheses).

A main effect of side was observed $[F(3,69)=79.45$, $\left.M S_{\mathrm{e}}=388.59, p<.0001\right]$. Responses made to targets presented at the same location as that for the cue were made more slowly $(M=383 \mathrm{msec})$ than were responses made to targets presented at the opposite location $(M=$ $341 \mathrm{msec}$ ), which is the standard IOR effect. The RTs to targets presented at the adjacent locations $\left(M_{\text {adj. left }}=\right.$ $354 \mathrm{msec}, M_{\text {adj. right }}=352 \mathrm{msec}$ ) were not responded to differently but were responded to more quickly than targets presented at the same location $[t(23)=14.56, p<$ $.0001]$ and more slowly than responses to targets presented at the opposite location $[t(23)=4.30, p=.003]$. This pattern of results is what would be predicted on the basis of attentional momentum.

An interaction was also observed between side and direction $\left[F(9,207)=8.08, M S_{\mathrm{e}}=222.92, p<.0001\right]$. Planned comparisons revealed that this interaction was due to the IOR effect's being larger when attention was moving either from left to right or from top to bottom than when it moved from right to left or from bottom to top [left to right vs. right to left, $t(23)=2.40, p=.025$; left to right vs. bottom to top, $t(23)=3.25, p=.003$; top to bottom vs. right to left, $t(23)=2.85, p=.009$; top to bottom vs. bottom to top, $t(23)=3.65, p=.001]$. But there was no difference in the IOR effects when attention was moving from left to right versus from top to bottom $[t(23)=0.96$, $p=.347]$. Nor was there a difference between the IOR effects when attention was moving from right to left versus from bottom to top $[t(23)=1.40, p=.175]$.

Further evidence for these biases was also observed when the adjacent locations were examined. When the initial cue was on the horizontal midline, the top and the bottom locations were equally eccentric from the cued location and were $90^{\circ}$ off the implied path that attention was traveling. Therefore, there should have been no difference in RTs for detecting a target presented at these two locations, according to the inhibition theories, as well as the attentional momentum view. However, when a horizontal cue was presented, the bottom location $(M=343 \mathrm{msec})$ was responded to significantly more quickly than the top location $[M=363 \mathrm{msec} ; t(23)=5.78, p<.0001]$, which would be consistent with a top-to-bottom bias. Similarly, when a cue was presented on the vertical midline, the left and the right locations were equally eccentric from the cued location and were $90^{\circ}$ off the implied path that attention was traveling. In this situation, the right location $(M=349 \mathrm{msec})$ was responded to significantly more quickly than the left location $[M=356 \mathrm{msec} ; t(23)=$ $2.45, p=.022]$. This would be consistent with a left-toright bias, because the participant would have been at fixation just prior to the target, so going to the right location would be consistent with the left-to-right movement of attention, whereas going to the left location would require 


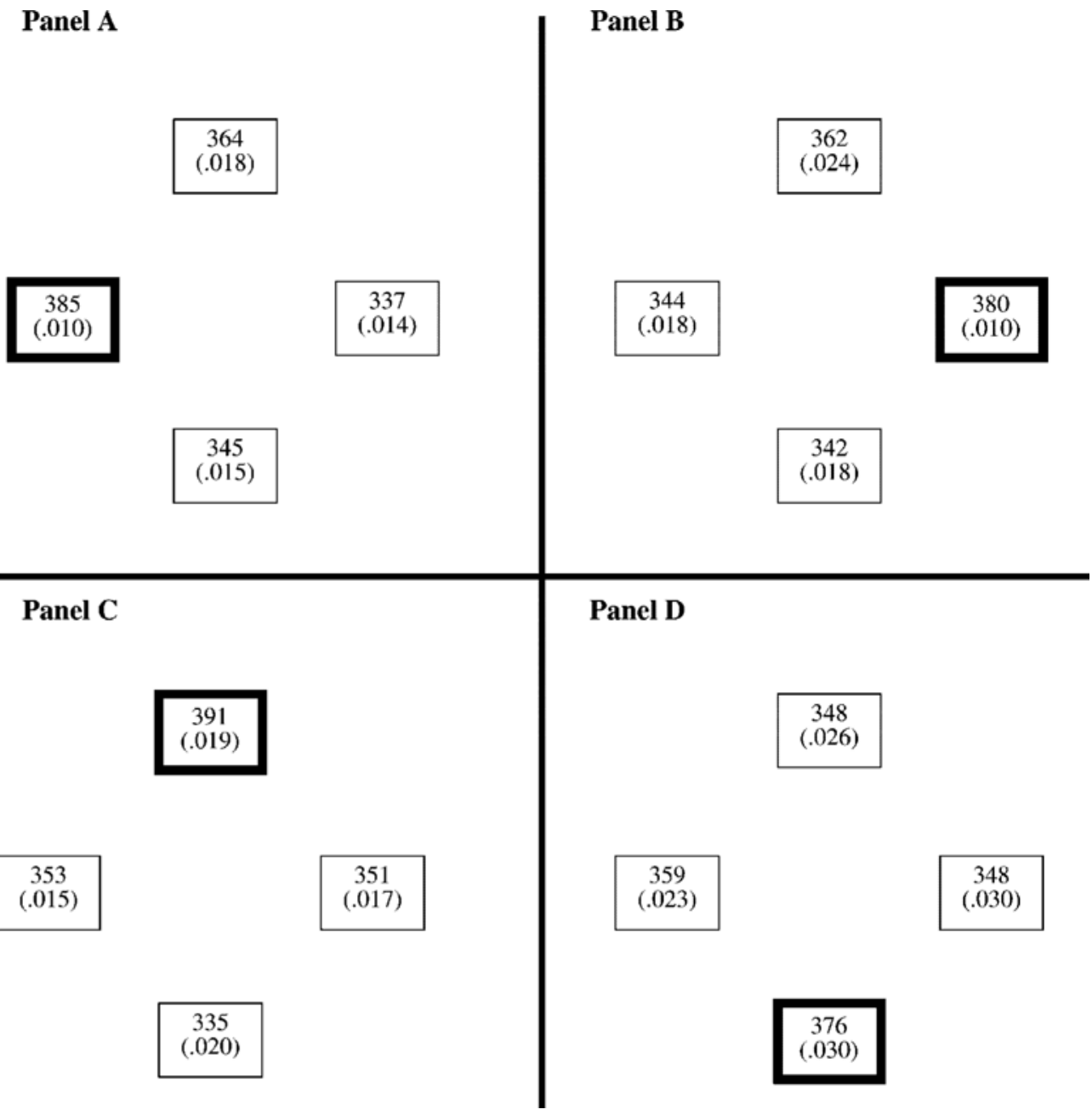

Figure 4. Experiment 2, “+” condition. Mean reaction times (in milliseconds) to target locations (mean response errors shown in parentheses) in the (A) left-right, (B) right-left, (C) top-bottom, and (D) bottom-top conditions (cue locations highlighted).

going against the bias. Thus, once again, left-to-right and top-to-bottom biases were observed in the IOR effect.

\section{EXPERIMENT 3}

Experiments 1 and 2 provide strong evidence that both a left-to-right and a top-to-bottom bias are present in the IOR effect. That is, the IOR effect is stronger when attention is moving from left to right or from top to bottom. However, the procedure that has been used might lead one to argue that the motion biases are simply due to apparent motion created by cuing the fixation location after the initial cue. That is, seeing the left location cued, followed by a cuing of the fixation location, might produce a situation similar to the phi phenomenon, whereby it appears that the cue is moving from left to right (Wertheimer, 1912). If this is true, the differential RTs at the uncued locations and the biases might be due to this apparent motion. The present experiment was conducted using the same procedure as that in Experiment 2, except without the use of a fixation cue. Past studies (e.g., Posner \& Cohen, 1984) have shown that IOR can be observed without a cue back to fixation if at least 300 msec elapses between the onset of the cue and the presentation of the target. Therefore, if the results of the previous experiments were due to apparent motion, they should not occur when the fixation cue is not presented. However, if the results were characteristic of the processes responsible for IOR, they should still be observed even when apparent motion cues are not present.

\section{Method}

Participants. The participants were 29 1st-year psychology students from the University of Toronto at Scarborough, who had not taken part in either Experiment 1 or 2 . They received course credit for their participation. All had normal or corrected-to-normal vision.

Procedure. The procedure was identical to that in Experiment 2, except that no fixation cue was used. Thus, after the initial cue of $300 \mathrm{msec}$, only the placeholders were displayed for $650 \mathrm{msec}$, before the target was presented. 


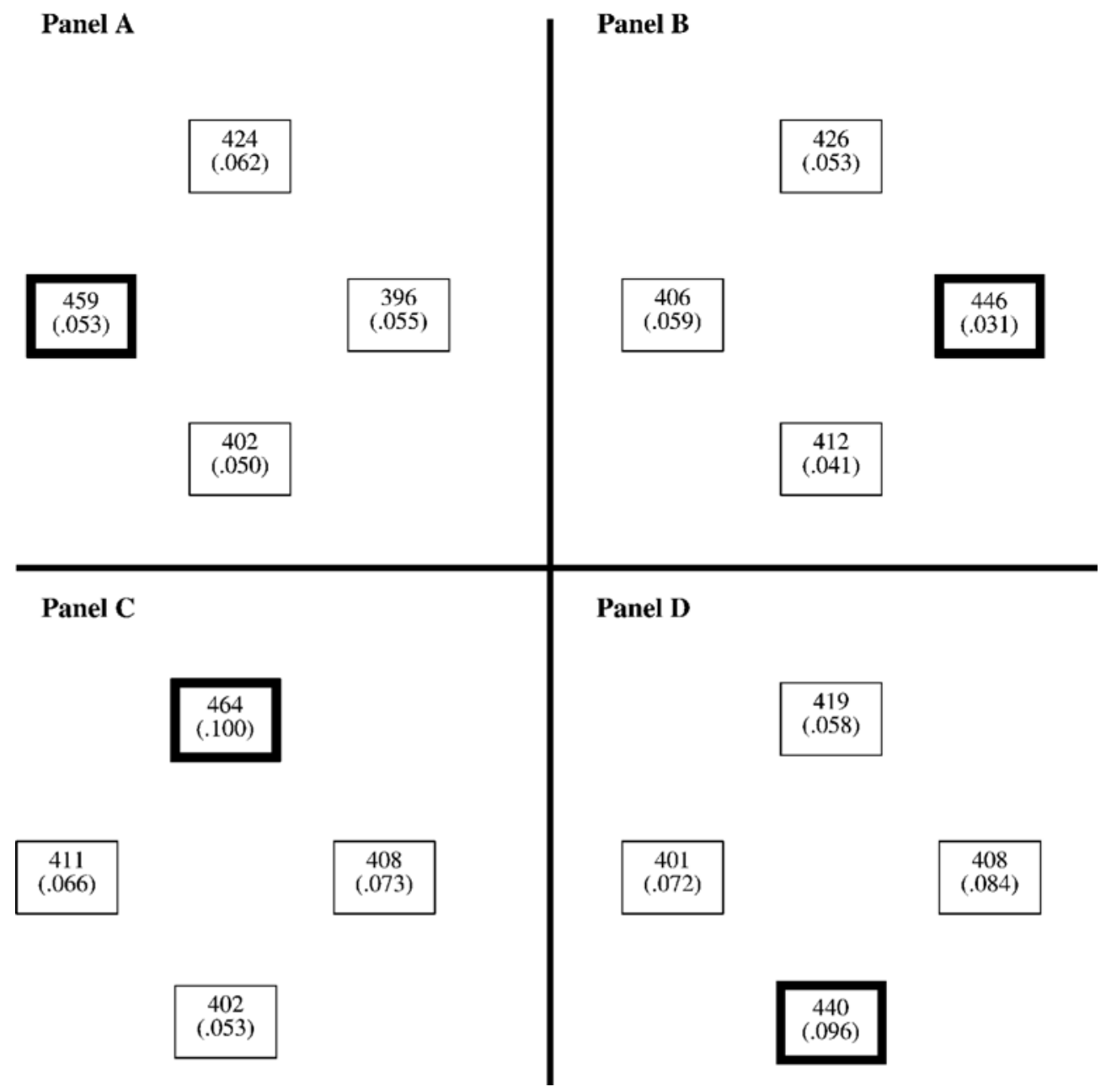

Figure 5. Experiment 3, “+” condition. Mean reaction times (in milliseconds) to target locations (mean response errors shown in parentheses) in the (A) left-right, (B) right-left, (C) top-bottom, and (D) bottom-top conditions (cue locations highlighted).

Design. Experiment 3 was made up of two blocks of trials. Each block began with 15 practice trials, followed by 192 test trials, 32 of which were randomly assigned as catch trials. Both the cue and the target had an equal probability of occurring in any of the four placeholders. Prior to each block of trials, a set of instructions was presented in written form. At the end of the first block of trials, a self-paced break was given to the participants. The participants could continue on to the second block at their leisure by depressing the "g" key. On average, the participants took a break approximately $2 \mathrm{~min}$ in length.

Apparatus and Materials. The apparatus and materials for the present experiment were identical to those in Experiments 1 and 2.

\section{Results and Discussion}

The RTs for 4 of the participants were excluded, due to the fact that in one of the conditions their means differed by more than two standard deviations from the mean of the rest of the participants. The RTs for the correct trials from the remaining 25 participants were analyzed with a two-way repeated measures ANOVA, with direction (left to right, right to left, top to bottom, and bottom to top) and side (same, opposite, adjacent left, and adjacent right) as within-subjects variables. All the participants were at least $80 \%$ accurate on the catch trials. The mean RTs for each condition are illustrated in Figure 5 (mean errors for these conditions are indicated in parentheses).

A main effect of side was observed $[F(3,72)=41.29$, $\left.M S_{\mathrm{e}}=1,120.00, p<.0001\right]$. Responses to targets presented at the same side as that for the cue were made more slowly $(M=452 \mathrm{msec})$ than responses to targets presented on the opposite side $(M=406 \mathrm{msec})$, which is the standard IOR effect. The RTs to targets presented at the adjacent locations were not different from each other $\left(M_{\text {adj. left }}=411 \mathrm{msec}, M_{\text {adj. right }}=412 \mathrm{msec}\right)$, but these responses were made more quickly than those to targets presented at the same location $[t(24)=7.68, p<.0001]$, and $[t(24)=1.79, p=.086]$. On the basis of the previous experiments (as well as the work of Pratt et al., 1999), a significant difference between the adjacent locations and the opposite location would have been expected. The lack of significance, though, was due to the unusual finding that the adjacent locations were actually responded to signifi- 
cantly more quickly than the opposite location following an initial cue at the bottom location $[t(24)=2.26, p=$ $.034]$. Given that there is a bias against upward movement, the opposite location would be expected to be responded to more slowly, and, hence, more like the adjacent locations. The fact that the IOR effect was not even significant in this condition $[t(24)=1.94, p=.065]$ and that this faster responding to the adjacent locations was not observed in Experiment 2 suggests that the effect may have been due to noise. If the initial bottom cue condition is excluded, the pattern of results is exactly what would be predicted on the basis of attentional momentum.

An interaction was also observed between side and direction $\left[F(9,216)=5.01, M S_{\mathrm{e}}=652.73, p<.0001\right]$. Planned comparisons revealed that this interaction was due to the IOR effect's being larger when attention moved either from left to right or from top to bottom than when it moved from right to left or from bottom to top [left to right vs. right to left, $t(24)=2.11, p=.045$; left to right vs. bottom to top, $t(24)=4.15, p=.0003$; top to bottom vs. right to left, $t(24)=2.60, p=.016$; top to bottom vs. bottom to top, $t(24)=3.25, p=.003$ ]. There was also a trend for a difference between the IOR effects when attention moved right to left versus bottom to top $[t(24)=1.72, p=.099]$. But there was no difference in the IOR effects when attention moved left to right versus top to bottom $[t(24)<1]$. Thus, once again evidence for both a left-to-right and a topto-bottom bias to the IOR effect was observed, despite the fact that no fixation cue was used in this experiment.

Further support for the top-to-bottom bias was observed at the adjacent locations following an initial cue that had occurred along the horizontal midline of the screen. As was pointed out in the Discussion section in Experiment 2, if no top-to-bottom bias was present, there should be no difference between these locations. However, again a difference was observed between these locations, so that the bottom location $(M=407 \mathrm{msec})$ was responded to significantly more quickly than the top location $[M=$ $425 \mathrm{msec} ; t(24)=4.17, p=.0003]$. Thus, overall, the data from the present experiment strengthen the notion that both a left-to-right and a top-to-bottom bias are present, and the fact that these results were obtained without a cue back to fixation suggests that the reported biases were not due to apparent motion but, rather, were a characteristic of IOR not previously known.

\section{GENERAL DISCUSSION}

Human beings actively engage in a wide variety of search behaviors every day of their lives. In order for those searches to be carried out in an efficient manner, we need some mechanism that encourages the orienting of attention toward novel locations. Two theoretical accounts of such a mechanism have previously been put forth: the inhibition account (e.g., Posner \& Cohen, 1984) and the attentional momentum account (Pratt et al., 1999). Pratt et al. (1999) conducted a series of experiments that contrasted these two views and concluded that their data favored the attentional momentum interpretation. The pres- ent article further evaluated the legitimacy of the attentional momentum account.

Pratt et al.'s (1999) conclusions hinged on the fact that they found different RTs at the various uncued locations. Recall that Posner and Cohen (1984) claimed that there was no difference in the RTs to the various uncued locations in their experiments. Therefore, it was imperative, as a first step, to see which of the two findings would be replicated and, thus, which view would be supported. In all of the experiments conducted, a difference between the various uncued locations was observed. Furthermore, the pattern of RTs fit the predictions that would be generated on the basis of the attentional momentum account. It is unclear why Posner and Cohen did not observe the differential RTs between the opposite and the adjacent locations. They did not report the RTs for the different locations and also did not provide the numbers of participants tested, so it may have been a power issue.

Another issue that raised problems for the attentional momentum account was uncovered in the literature. This was the finding by O'Donnell and Pratt (1996) that if a near location was cued, no IOR was observed at the far locations. They suggested that inhibition was allocated only to locations that attention had previously traversed over and, since attention had never made it out as far as the far location, no inhibition would be directed there. Attentional momentum, on the other hand, would have predicted that responses to targets presented at any locations on the same side as the cue would be made more slowly, regardless of whether attention had been directed to that location or not. Thus, if O' Donnell and Pratt's results were reliable, they would be very difficult to account for with the notion of attentional momentum. Making the interpretation of O'Donnell and Pratt's findings controversial was the fact that although statistically the data did not allow for the conclusion that IOR occurred at the far locations following a near cue, qualitatively the data were in the direction favoring that conclusion.

Thus, in the present study, Experiment 1 was designed to investigate this finding, using a more powerful design, and to determine whether this truly raised problems for the attentional momentum account. The results of Experiment 1 in the present article did allow for the conclusion that IOR is observable at the far locations following a near cue, as the attentional momentum account would predict. Indeed, as attentional momentum would predict, all the locations on the cued side were responded to more slowly than locations equidistant from fixation, but on the opposite side. Therefore, neither of the two concerns raised provides a genuine problem for the attentional momentum view; instead, they provide support for the inclusion of attentional momentum as an account for the IOR phenomenon.

A third focus of this article was to investigate whether the attentional system is biased toward moving in a particular direction. In the memory literature, a directional bias has been observed in the phenomenon known as representational momentum (Freyd \& Finke, 1984). This directional bias was of the form that the participants judged the final position of an object as being further along its 
trajectory when the implied movement was from left to right (Halpern \& Kelly, 1993) or from top to bottom (Hubbard, 1990). Thus, the present set of experiments assessed the degree to which any directional bias was present in the IOR phenomenon.

The results from Experiments 1, 2, and 3 showed that a bias is present in the IOR effect. Although somewhat confounded, the results of Experiment 1 seemed to indicate that both a left-to-right bias and a top-to-bottom bias were present and that both biases were approximately the same strength. In Experiments 2 and 3, we sought to separate out any top-to-bottom bias from the left-to-right bias and found evidence that both biases are present in the IOR effect. In addition, Experiment 3 ruled out the possibility that the findings from the first two experiments were due to the creation of apparent motion between the initial cue and the fixation cue, because no fixation cue was used in Experiment 3, yet all of the critical findings from Experiment 2 were replicated. Therefore, both a left-to-right and a top-to-bottom bias exists in the IOR effect, and to the extent that IOR is an attentional phenomenon, this implies that there is a left-toright and a top-to-bottom bias to the movement of attention.

The present article has focused on dispelling two problematic findings that previously existed in the IOR literature. Does this mean that there are no further challenges to the attentional momentum view? This is definitely not the case. For example, Berlucchi et al. (2000) found that IOR occurs despite the fact that $5 \mathrm{sec}$ has elapsed between the initial cue and target presentation. Tipper, Grison, and Kessler (2003) found IOR-like effects for pictures of faces that lasted for $13 \mathrm{~min}$ between the cue and target presentation, and with numerous trials intervening. If the IOR effect simply reflects attention in motion, as attentional momentum implies, it is hard to imagine that attention would continue to be in motion for that length of time. Therefore, it seems reasonable to speculate that memory plays a role in the IOR phenomenon, and one possibility is that the processing at the time at which the cue is presented is reinstatiated when the target is presented (e.g., Tipper et al., 2003). In fact, it is likely that the left-to-right bias that was observed in the present study reflects the learning of some environmental regularity, such as the movement that occurs when printed text is read. If it is accepted that memory is involved in the IOR phenomenon, the finding of similar biases in the IOR and the representational momentum phenomena is less surprising. Additional support for a linkage between attention and memory is provided by the finding that dividing attention results in an increase in the size of the representational momentum effect (Hayes \& Freyd, 2002). Therefore, if the attentional momentum explanation for IOR is correct, it may be the case that a similar momentum mechanism underlies both phenomena. But any direct linkage between the two phenomena awaits further investigation.

Another finding with respect to IOR that attentional momentum has difficulty accounting for is the finding that IOR seems to be associated not only with a previously attended location in space, but also with the object that had previously been attended (Tipper, Weaver, Jerreat, \&
Burak, 1994). In the present study and in most IOR studies, these two components are summed together, because the cued object remains in the cued location. However, if attention is moved to a new object/location and then the original object is moved, one can identify the IOR effect that occurs if attention is moved back to the old location or if attention is moved to the location where the old object is now residing. Attentional momentum posits that attention will move along a vector from the first location to the second, and so returning to the original location will go against the momentum. But it is difficult to identify a way that attentional momentum could account for the object-based IOR effect. It may be that two different mechanisms will be required to explain IOR under static and dynamic cuing conditions, with attentional momentum potentially explaining the location-based IOR and something else accounting for the object-based IOR. If this were the case, one might expect that different brain areas would be responsible for the two types of IOR. In fact, researchers have found evidence that the two components seem to arise as a result of different neural systems, with the location-based IOR component being mediated by the superior colliculus and the object-based IOR component being mediated by cortical structures (see Tipper et al., 1997, for further discussion).

To summarize, then, the purpose of the present set of experiments was to evaluate the attentional momentum view as an explanation of the IOR phenomenon. Previous problematic results (O'Donnell \& Pratt, 1996; Posner \& Cohen, 1984) for the attentional momentum view were not replicated, and instead the results that would be predicted on the basis of the attentional momentum account were observed. As well, a bias to the IOR effect was identified, and this bias is similar to that observed in the memory literature in which another momentum account has been used as an explanation. Thus, the attentional momentum account deserves serious consideration as an explanation for the IOR effect.

\section{REFERENCES}

ABRAMS, R. A., \& DOBKIN, R. S. (1994). Inhibition of return: Effects of attentional cueing on eye movement latencies. Journal of Experimental Psychology: Human Perception \& Performance, 20, 467-477.

Berlucchi, G., Chelazzi, L., \& TAssinari, G. (2000). Volitional covert orienting to a peripheral cue does not suppress cue-induced inhibition of return. Journal of Cognitive Neuroscience, 12, 648-663.

Chasteen, A. L., \& Pratt, J. (1999). The effect of inhibition of return on lexical access. Psychological Science, 10, 41-46.

FREYD, J. J., \& FINKE, R. A. (1984). Representational momentum. Journal of Experimental Psychology: Learning, Memory, \& Cognition, 10, 126-132.

Graves, R., \& BRADLEY, R. (1987). Millisecond interval timer and auditory reaction time programs for the IBM PC. Behavior Research Methods, Instruments, \& Computers, 19, 30-35.

Graves, R., \& Bradley, R. (1988). More on millisecond timing and tachistoscope applications for the IBM PC. Behavior Research Methods, Instruments, \& Computers, 20, 408-412.

Halpern, A. R., \& Kelly, M. H. (1993). Memory biases in left versus right implied motion. Journal of Experimental Psychology: Learning, Memory, \& Cognition, 19, 471-484.

Handy, T. C., Jha, A. P., \& Mangun, G. R. (1999). Promoting novelty in vision: Inhibition of return modulates perceptual-level processing. Psychological Science, 10, 157-161. 
HAYES, A. E., \& FREYd, J. J. (2002). Representational momentum when attention is divided. Visual Cognition, 9, 8-27.

HubBARD, T. L. (1990). Cognitive representation of linear motion: Possible direction and gravity effects in judged displacement. Memory \& Cognition, 18, 299-309.

Lupiáñez, J., Milan, E. G., Tornay, F. J., Madrid, E., \& Tudela, P. (1997). Does IOR occur in discrimination tasks? Yes, it does, but later. Perception \& Psychophysics, 59, 1241-1254.

MAYLOR, E. (1985). Facilitatory and inhibitory components of orienting in visual space. In M. I. Posner \& O. S. M. Marin (Eds.), Attention \& performance XI (pp. 189-204) Hillsdale, NJ: Erlbaum.

MCDONALD, J. J., \& WARD, L. M. (1999). Spatial relevance determines facilitatory and inhibitory effects of auditory covert spatial orienting. Journal of Experimental Psychology: Human Perception \& Performance, 25, 1234-1252.

McDonald, J. J., Ward, L. M., \& Kiehl, K.A. (1999). An eventrelated brain potential study of inhibition of return. Perception \& Psychophysics, 61, 1411-1423.

Mondor, T. A. (1999). Predictability of the cue-target relation and the time-course of auditory inhibition of return. Perception \& Psychophysics, 61, 1501-1509.

O'Donnell, C., \& PRATT, J. (1996). Inhibition of return along the path of attention. Canadian Journal of Experimental Psychology, 50, 386-392.

Posner, M. I., \& COHEN, Y. (1984). Components of visual orienting. In H. Bouma \& D. G. Bouwhuis (Eds.), Attention and performance X: Control of language processes (pp. 531-556). Hillsdale, NJ: Erlbaum.

Posner, M. I., RAfal, R. D., ChOATE, L., \& VAughan, J. (1985). Inhibition of return: Neural basis and function. Cognitive Neuropsychology, 2, 211-228.

PratT, J. (1995). Inhibition of return in a discrimination task. Psychonomic Bulletin \& Review, 2, 117-120.

Pratt, J., AdAM, J. J., \& MCAUlifFe, J. (1998). The spatial relationship between cues and targets mediates inhibition of return. Canadian Journal of Experimental Psychology, 52, 213-216.

Pratt, J., Kingstone, A., \& KhoE, W. (1997). Inhibition of return in location- and identity-based choice decision tasks. Perception \& Psychophysics, 59, 964-971.

Pratt, J., Spale K, T. M., \& Bradshaw, F. (1999). The time to detect targets at inhibited and noninhibited locations: Preliminary evidence for attentional momentum. Journal of Experimental Psychology: Human Perception \& Performance, 25, 730-746.

Rafal, R. D., Calabresi, P. A., Brennan, C. W., \& Sciolto, T. K. (1989). Saccade preparation inhibits reorienting to recently attended locations. Journal of Experimental Psychology: Human Perception \& Performance, 15, 673-685.

Reuter-Lorenz, P. A., JhA, A. P., \& Rosenquist, J. N. (1996). What is inhibited in inhibition of return? Journal of Experimental Psychology: Human Perception \& Performance, 22, 367-378.

RÖDER, B., SPENCE, C., \& RöSLER, F. (2000). Inhibition of return and oculomotor control in the blind. NeuroReport, 11, 3043-3045.
SCHMidT, W. C. (1996). "Inhibition of return" without visual input. Neuropsychologia, 34, 943-952.

SPENCE, C., \& DRIVER, J. (1998). Auditory and audiovisual inhibition of return. Perception \& Psychophysics, 60, 125-139.

SPence, C., Lloyd, D., MCGlone, F., Nicholls, M. E. R., \& Driver, J. (2000). Inhibition of return is supramodal: A demonstration between all possible pairings of vision, touch and audition. Experimental Brain Research, 134, 42-48.

TANAKA, Y., \& Shimojo, S. H. (1996). Location vs. feature: Reaction time reveals dissociation between two visual functions. Vision Research, 36, 2125-2140.

TAYLOR, T. L., \& KLEIN, R. M. (1998). On the causes and effects of inhibition of return. Psychonomic Bulletin \& Review, 5, 625-643.

Terry, K. M., VAldes, L. A., \& NeILl, W. T. (1994). Does “inhibition of return" occur in discrimination tasks? Perception \& Psychophysics, 55, 279-286.

TIPPER, S. P., GRISON, S., \& KESSLER, K. (2003). Long-term inhibition of return of attention. Psychological Science, 14, 19-25.

Tipper, S. P., Rafal, R., Reuter-Lorenz, P. A., Starrveldt, Y., Ro, T., Egly, R., \& WEAVER, B. (1997). Object-based facilitation and inhibition from visual orienting in the human split-brain. Journal of Experimental Psychology: Human Perception \& Performance, 23, 1522-1532.

Tipper, S. P., WeAver, B., Jerreat, L., \& Burak, A. (1994). Objectand environment-based inhibition of return of visual attention. Journal of Experimental Psychology: Human Perception \& Performance, 20, 478-499.

VAUGHAN, J. (1984). Saccades directed at previously attended locations in space. In A. G. Gale \& F. Johnson (Eds.), Theoretical and applied aspects of eye movement research (pp. 143-150). Amsterdam: NorthHolland.

Wertheimer, M. (1912). Experimentelle Studien über das Sehen von Bewegung. Zeitschrift für Psychologie, 61, 161-265.

YANTIS, S., \& JONIDES, J. (1990). Abrupt visual onsets and selective attention: Voluntary versus automatic allocation. Journal of Experimental Psychology: Human Perception \& Performance, 16, 121-134.

\section{NOTES}

1. We also conducted the analysis as a three-way repeated measures ANOVA, with Direction 1 (left/right), Direction 2 (top/bottom), and side (same/opposite) as factors, with similar results. There was a main effect of Direction $1\left[F(1,40)=4.47, M S_{\mathrm{e}}=335.52, p=.041\right]$, a main effect of side $\left[F(1,40)=87.34, M S_{\mathrm{e}}=621.72, p<.0001\right]$, an interaction indicating that there was a significant left-to-right bias in the IOR effect $\left[F(1,40)=12.04, M S_{\mathrm{e}}=234.45, p=.001\right]$, and an interaction indicating that there was a significant top-to-bottom bias in the IOR effect $\left[F(1,40)=16.80, M S_{\mathrm{e}}=244.55, p=.0002\right]$. There was no three-way interaction, suggesting that the two biases were additive to one another $[F(1,40)<1]$. 


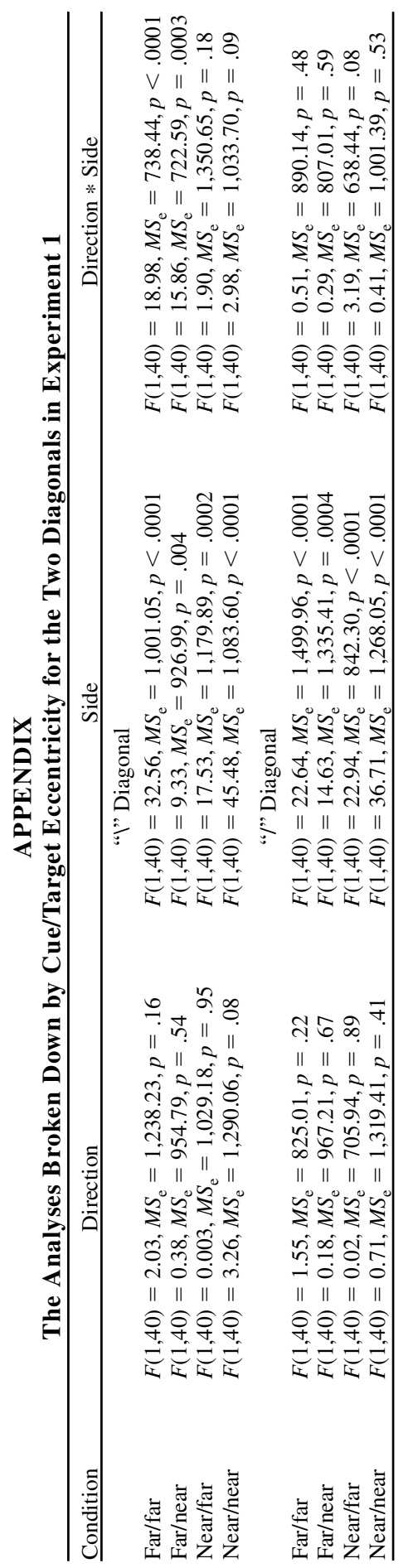

(Manuscript received August 6, 2001;

revision accepted for publication June 25, 2003.) 